\title{
The Outpatient Clinic Visit: Expectations and Fulfilment of Perceived Needs in Adolescents with Type 1 Diabetes
}

\author{
Daniel Novak ${ }^{1,2}$, John Eric Chaplin'1, Gun Forsander ${ }^{1,2}$ \\ ${ }^{1}$ Department of Pediatrics, Institute for Clinical Sciences, Sahlgrenska Academy, University of Gothenburg, Gothenburg, Sweden \\ ${ }^{2}$ Region Västra Götaland, Sahlgrenska University Hospital, and the Queen Silvia Children's Hospital, Department of Pediatrics, \\ Gothenburg, Sweden \\ Email: Gun.forsander@vgregion.se
}

How to cite this paper: Novak, D., Chaplin, J.E. and Forsander, G. (2021) The Outpatient Clinic Visit: Expectations and Fulfilment of Perceived Needs in Adolescents with Type 1 Diabetes. Journal of Diabetes Mellitus, 11, 52-67.

https://doi.org/10.4236/jdm.2021.112005

Received: March 10, 2021

Accepted: May 18, 2021

Published: May 21, 2021

Copyright $\odot 2021$ by author(s) and Scientific Research Publishing Inc. This work is licensed under the Creative Commons Attribution International License (CC BY 4.0).

http://creativecommons.org/licenses/by/4.0/ (c) (i) Open Access

\begin{abstract}
Background: To make outpatient visits for adolescents with diabetes successful, it is important for health care professionals to meet the adolescents' needs and wishes. Aims: The aim is to investigate adolescents' expectations of an outpatient diabetes clinic visit in comparison to what was deemed to be delivered and contrast this outcome in adolescents with self-reported highand low-diabetes distress respectively. Methods: All adolescents in Sweden with type 1 diabetes, aged 15 to 18 years, were identified via The National Pediatric Diabetes Registry (SWEDIABKIDS) and asked to complete an online questionnaire regarding their expectations and the support received during the outpatient diabetes clinic visit. Results: 453 adolescents completed the survey. Boys' expectations of discussion topics were mainly met while girls, especially those with diabetes distress, felt their discussion needs were not met regarding quality-of-life aspects. Conclusions: Although adolescents' expectations are in general met during the diabetes outpatient clinic visit, aspects related to living with diabetes are not being met especially among female adolescents who reported diabetes distress. This study shows a gender difference both regarding expected discussion topics and what was deemed covered. Practice Implications: A multi-professional, individual person-centred care approach is needed at the diabetes outpatient clinic. This paper proposes that agenda setting performed by the adolescent, and agreed by the physician, prior to the outpatient clinic visit could facilitate individualized care and better meet the adolescents' needs in a shared decision-making process.
\end{abstract}

\section{Keywords}

Adolescents, Type 1 Diabetes, Diabetes Distress, Gender, Expectations, Outpatient Clinic Visit, Agenda Setting 


\section{Introduction}

Adolescence is a period that is particularly challenging in combination with type 1 diabetes (T1D). During adolescence, the risk of future cardiovascular complications accelerates, with girls having a greater risk than boys [1]. As a group, adolescent girls have worse metabolic control than boys [2] [3] [4]. They have a higher risk for diabetes ketoacidosis (DKA), dyslipidaemia and weight problems, and smoke at a higher rate than boys [2] [3] [4] [5]. A large proportion of adolescents do not reach the target level of glycated haemoglobin, HbA1c [6] [7]. Even though the average HbAlc is decreasing among adolescents in Sweden, they still have a significantly higher HbA1c than pre-pubertal children [3].

Adolescence is a psychologically vulnerable period. Adolescents with T1D are at an increased risk for mental health problems, such as eating and behavioural disorders and depressive symptoms, compared with adolescents without T1D [8] [9] [10]. Girls with T1D report a lower quality of life compared with boys [11], and also have a higher rate of diabetes distress compared with adolescent boys [12]. Diabetes distress is defined as an emotional response toward adverse or unpleasant stress related to diabetes and has been related to a decline in self-management behaviours and suboptimal plasma glucose levels [13]. Altogether, adolescence is a vulnerable period where health care professionals (HCPs) play a vital role in supporting and promoting both physical and mental health in those with T1D.

A national survey of adolescents with T1D, the Teenagers on Diabetes Sweden (TODS) was carried out which provided information about the main drivers and barriers for optimal treatment of T1D among Swedish adolescents [12] [14]. The first part of the study concluded that the pediatric diabetes teams working with teenagers must intensify the care during this period of life in order to reduce the risk of both psychological and vascular complications in young adults [12]. The second part of the TODS' study concluded that adolescents prioritize different aspects of the diabetes care. By using a discrete choice experiment model, i.e. a "willingness-to-pay" methodology, it was for example shown that female respondents were willing to trade off a substantial level of glycemic control ([13] $\mathrm{mmol} / \mathrm{mol}(1.2 \%))$ to avoid a weight gain of $3 \mathrm{~kg}$ [14].

In line with these earlier findings, the aim of this third part of the TODS study was to investigate the expectations of a diabetes outpatient clinic visit compared with what was perceived to be delivered. Met and unmet needs were further compared between adolescents with diabetes distress and those without.

\section{Methods}

\subsection{Study Design and Study Population}

The design of the main study is described in detail elsewhere [12] [14] and was performed in the year 2016. The national Swedish Pediatric Diabetes Quality Registry (SWEDIABKIDS) was used to find participants who were eligible for enrolment. The register includes data on almost all (approximately 99\%) children and 
adolescents under the age of 18 who have diabetes in Sweden [15]. Following ethical approval, all adolescents in the SWEDIABKIDS registry aged from fifteen to their eighteenth birthday ( 15 to $<18$ years) with T1D were sent an invitation letter by surface mail to complete an online questionnaire accessible through a website designed specifically for the study. A total of 2112 eligible teenagers were identified through SWEDIABKIDS (53.3\% boys) and asked to participate in the study by a letter. Non-responders were sent one reminding letter (Figure 1).

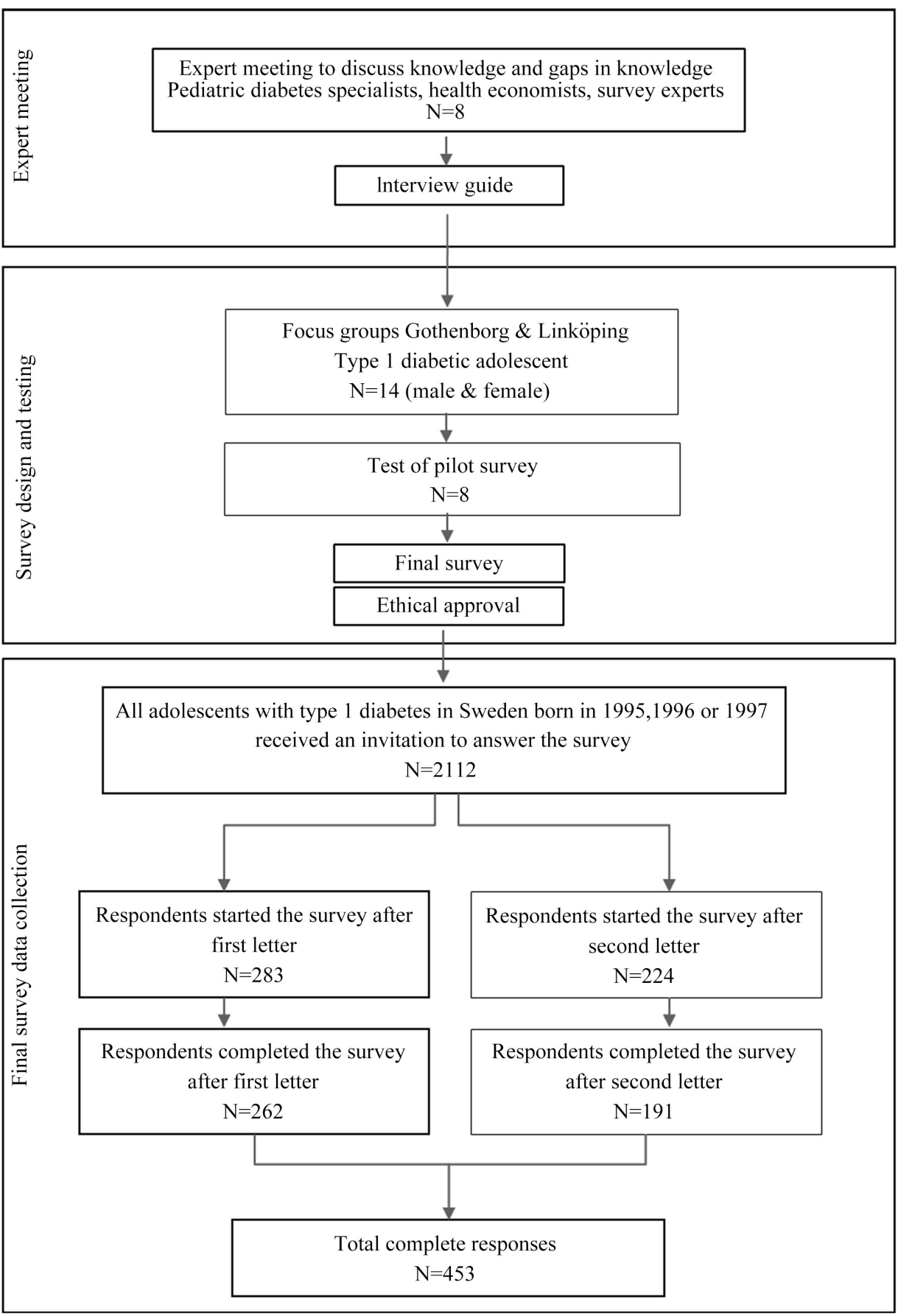

Figure 1. Flowchart on the inclusion procedure in the TODS study. 


\subsection{Expectations of the Outpatient Visit}

Focus groups and questionnaire construction

The adolescents' expectations for the most recent outpatient visit with the pediatric diabetologist and diabetes nurse was evaluated. Two gender specific group discussion were conducted (seven boys and seven girls aged 15 to $<18$ years) using by a semi-structured protocol to elicit expectations of the clinical visits. The groups were moderated by a person trained in focus group technique at two different pediatric clinics (Gothenburg and Linköping). Following the analysis of the focus group data, ten themes or expectations were identified for discussion in the optimal outpatient clinic visit which could be categorized into three domains of medical information, life-style indicators, and social support (Table 1). Using these themes, a questionnaire was constructed which in turn was tested for relevance and ambiguity by eight individuals (four boys and four girls, aged 15 to $<18$ years) in a cognitive debriefing process. The themes included in the questionnaire were: insulin treatment, $\mathrm{HbAlc}$, facts about diabetes, how your life is, how to live a good life with diabetes, diet, exercise, alcohol, smoking, sex and relationships.

On-line questionnaire

Questions concerning these expectations were then developed. The importance of discussing each theme at the outpatient clinic visit was graded on a 4-point Likert scale ranging from 1 ("very little extent") to 4 ("very great extent"). The adolescents then graded how well these themes were covered during the visit, also ranging from 1 ("very little extent") to 4 ("very great extent").

The online questionnaire included questions regarding; the medical condition and current insulin treatment, preference for diabetes treatment (including outpatient visits), self-care behaviour, and socio-demographic information. In addition the brief screening version of the diabetes distress scale (DDS-2) derived from DDS-17 [16] [17] was completed. The DDS-2 is composed of two items relating to the individual experiences during the last month: 1) "feeling overwhelmed by the demands of living with diabetes", and 2) "feeling that I am often

Table 1. Theme discussion categories in outpatient clinic visit.

\begin{tabular}{cc}
\hline Domains & $\begin{array}{c}\text { Adolescents focus group's ten emerging } \\
\text { themes expected to be discussed in the consultation }\end{array}$ \\
Facts about diabetes; \\
Insulin treatment; \\
Hedical information \\
Diet; \\
Exercise; \\
Alcohol \\
Smoking \\
Sex and relationships \\
Social support \\
Current feelings \\
How to live a good life with diabetes
\end{tabular}


failing with my diabetes regimen". The score on each item ranged from 1 ("not a problem") to 6 ("a very serious problem") [18]. As suggested by Fisher et al. [18], we calculated the mean score and used a cut-off level of $\geq 3$ (moderate distress) on the DDS-2 to indicate a problem with diabetes distress. The DDS-2 correlates with the DDS-17 $(r=0.69)$ and the sensitivity and specificity has been found to be high ( 0.95 and 0.85$)$. The questions were professionally translated from their original English version to Swedish.

\subsection{Data from the SWEDIABKIDS Registry}

The survey sample was linked to diabetes information contained in the SWEDIABKIDS registry. From this data, we included measured HbAlc, duration of diabetes, age, and gender. The HbAlc measurement recorded most recently before the survey completion date was used. Duration of diabetes was calculated as the time between the first entry into the registry at the initial diabetes diagnosis and the survey start date.

\subsection{Statistical Methods}

We compared respondents with non-respondents using data from the SWEDIABKIDS registry, allowing comparison on gender, age, $\mathrm{HbA1c}$ and duration of diabetes. We tested for significant differences using t-tests and $\chi^{2}$ tests for continuous and categorical data. In the analysis of expectations of the outpatient visit we calculated two-sided $95 \%$ confidence limits (95\% CI) for the mean values. The confidence limits provide ranges of likely values for the true population means.

We performed a multivariate regression with an aim to identify parameters significantly associated with diabetes distress. All tests were two-tailed, and significance levels were set at $p<0.05$. The categorical independent variables included in the analysis were: HBAlc, gender, family economics, speaking about diabetes with friends, wish for parental involvement, and having high blood sugars to prevent hypoglycemia. All statistical analyses were carried out using SAS 9.4.

The DDS-2 score was dichotomised as having diabetes distress (average score $\geq 3$ ) and not having diabetes distress (average score $<3$ ). The independent variables included in the analysis were $\mathrm{HbAlc}$, gender, perceived family economy, not speaking about diabetes with friends, the wish for more parental involvement and having high blood sugar to prevent hypoglycaemia.

\subsection{Ethical Considerations}

The study was approved by the regional ethical review board and performed in accordance with the Declaration of Helsinki. The participants were informed in writing that their answers would be used for research and that their identity would not be revealed or linked to their responses. Both the adolescents and their parents were informed about the study prior to participation. It was em- 
phasized that participation in the survey was voluntary and that they could discontinue the survey at any stage. Contact information for the responsible researchers was made available both in the contact letter and on the study website.

\section{Results}

\subsection{Study Population}

A total of 507 individuals initiated the questionnaire. Fifty-four did not complete the survey, resulting in 453 complete responses. The data collection flow is illustrated in Figure 1. In a non-participation analysis, the characteristics of the respondents were compared with the non-respondents $(\mathrm{N}=1659)$. The respondents were not statistically different from non-respondents in terms of age and duration of diabetes. The mean age of respondents and non-respondents was both 17.0 years (SD: 0.8 and 0.9 , respectively), while the duration of diabetes was 6.6 years (SD: 3.6) in respondents and 6.7 years (SD: 3.5$)$ in non-respondents (n.s). More girls participated the study (298 vs 155 ) and the participants had on average significantly lower HbAlc $(\mathrm{p}<0.0001)$. The average $\mathrm{HbAlc}$ was 60 $\mathrm{mmol} / \mathrm{mol}$ (SD: 15$)$ (7.7\%, SD: 3.5$)$ in respondents and $66 \mathrm{mmol} / \mathrm{mol}$ (SD: 16) (8.2\%, SD: 3.6$)$ in non-respondents. There were $66 \%$ girls among respondents compared with $40 \%$ girls among the non-respondents. Since the responses did not differ significantly between the diabetes nurse and pediatric diabetologist, we only show the results of the expectations from the outpatient visit with regards to the pediatric diabetologist.

The data on the respondents is shown in Table 2. Among the respondents, there was no difference in age or duration of diabetes between girls and boys. Girls however had significantly worse metabolic control than boys with the most previous HbAlc measured among girls being $62 \mathrm{mmol} / \mathrm{mol}$ (7.9\%) and among boys $56 \mathrm{mmol} / \mathrm{mol}(7.3 \%)(\mathrm{p}<0.001)$. There was no significant gender difference in social factors between girl- and boy participants but significantly more girls than boys experienced diabetes distress (44\% vs 19\%).

\subsection{Expectations of the Outpatient Clinic Visit}

The themes derived from the focus groups were perceived as relevant by the respondents by means of cognitive debriefing. The results on what themes the adolescents wished to talk about at the clinical outpatient visit and to what extent they were fulfilled are presented in Figure 2. It shows a gender difference in met and unmet needs where more themes were perceived as unmet among the girls. The only themes that were met by both girls and boys were insulin treatment and HbAlc. Smoking, sex and relationships were discussion topics that were perceived as less important to talk about by adolescents and were also reported as less talked about during the outpatient visit. Girls, as compared to boys, reported a significantly higher degree of interest in discussing the following themes: insulin treatment, their $\mathrm{HbAlc}$, how they are feeling, how to live a good life with diabetes, diet, and exercise (data not shown). 


\subsection{Diabetes Distress}

Significantly more girls reported symptoms of diabetes distress (DDS-2 score $\geq$ 3) (boys: $\mathrm{n}=29,19 \%$; girls: $\mathrm{n}=130,44 \% ; \mathrm{p}<0.0001$ ). The multivariate regression analysis identified six independent parameters as significantly associated with diabetes distress presented in Table 3. Being a girl was the strongest parameter associated with having diabetes distress (OR: 2.8; 95\% CI: 1.69 - 4.64). Wishing for more parental support was the second strongest parameter associated with diabetes distress (OR: 1.56; 95\% CI: 1.25 - 1.94) however being able to speak to friends about diabetes was found to be a protective parameter against diabetes distress (OR: 0.42; 95\% CI: 0.27 - 0.66).

Table 2. Medical condition, Life-style indicators, Social support, diabetes distress, and socio-economic factors and social support-descriptive frequencies and gender differences.

\begin{tabular}{|c|c|c|c|}
\hline & Male respondents $(\mathrm{N}=155)$ & Female respondents $(\mathrm{N}=298)$ & p-value \\
\hline \multicolumn{4}{|l|}{ Medical condition } \\
\hline \multicolumn{4}{|l|}{ Latest measured HbA1c (SWEDIABKIDS registry) } \\
\hline - mmol/mol - mean (std.dev.) & $56(12.9)$ & $62.4(15.4)$ & $<0.0001$ \\
\hline - \%NSBG - mean (std.dev.) & $7.3(3.3)$ & $7.9(3.6)$ & $<0.0001$ \\
\hline Knows own Hbalc-value & & & \\
\hline $\begin{array}{l}\text { (report exact or interval estimate of own Hbalc Self-reported } \\
\qquad \text { HbAlc (a) }\end{array}$ & $88 \%$ & $89 \%$ & 0.6273 \\
\hline$-\mathrm{mmol} / \mathrm{mol}-$ mean (std.dev.) & $56.2(12.1)$ & $61.1(13.7)$ & 0.0006 \\
\hline - \%NSBG - mean (std.dev.) & $7.3(3.3)$ & $7.7(3.4)$ & 0.0006 \\
\hline $\begin{array}{l}\text { Duration of diabetes (measured by earliest registration in } \\
\text { SWEDIABKIDS registry) - mean (std.dev.) }\end{array}$ & $6.2(3.9)$ & $6.9(3.3)$ & 0.0548 \\
\hline Age - mean (std.dev.) & $16.9(0.8)$ & $17.1(0.8)$ & 0.048 \\
\hline \multicolumn{4}{|l|}{ Life-style indicators } \\
\hline Exercising $\geq 30$ min at least 2 days during last week (b) & $72 \%$ & $76 \%$ & 0.3621 \\
\hline Eating a healthy diet at least 4 days during last week (b) & $46 \%$ & $54 \%$ & 0.0839 \\
\hline Smoked on 1 or more occasions during last week (b) & $14 \%$ & $18 \%$ & 0.2472 \\
\hline Consumed alcohol on 1 or more occasions during last week (b) & $20 \%$ & $21 \%$ & 0.7763 \\
\hline \multicolumn{4}{|l|}{ Social support } \\
\hline Trust that parents can handle their diabetes when needed (c) & $91 \%$ & $91 \%$ & 0.9921 \\
\hline Wishes that parents were more involved in their diabetes care (c) & $9 \%$ & $18 \%$ & 0.0128 \\
\hline Talk with friend(s) about diabetes & $64 \%$ & $66 \%$ & 0.6871 \\
\hline \multicolumn{4}{|l|}{ Diabetes distress } \\
\hline Distressed (distress brief version screening score $\geq 3$ ) & $19 \%$ & $44 \%$ & $<0.0001$ \\
\hline Diabetes distress brief version screening score (mean) & 2.0 & 2.8 & $<0.0001$ \\
\hline \multicolumn{4}{|l|}{ Socio-economic factors } \\
\hline Family economic status evaluated as average or above average (c) & $92 \%$ & $88 \%$ & 0.1942 \\
\hline Living in one household with both parents & $70 \%$ & $69 \%$ & 0.9625 \\
\hline
\end{tabular}

(a) Includes self-reported exact number and midpoint of self-reported interval of Hbalc. (b) Dichotomized for this analysis from a $0-7$ days response option. (c) Dichotomized for this analysis from a multi-category response option. 
Table 3. Odds ratios (OR) and 95\% confidence intervals (95\% CI) for the association of a number of different parameters significantly associated with diabetes distress.

\begin{tabular}{|c|c|c|c|}
\hline & OR & $95 \%$ CI & p-value \\
\hline \multicolumn{4}{|l|}{ HbAlc } \\
\hline$\leq 52 \mathrm{mmol} / \mathrm{mol}(6.9 \%)$ & 1 & (Ref.) & (Ref.) \\
\hline$>52 \mathrm{mmol} / \mathrm{mol}(6.9 \%)$ & 1.62 & $(1.02-2.58)$ & 0.043 \\
\hline Do not know & 1.59 & $(0.77-3.26)$ & 0.207 \\
\hline \multicolumn{4}{|l|}{ Gender } \\
\hline Boys & 1 & (Ref.) & (Ref.) \\
\hline Girls & 2.80 & $(1.69-4.64)$ & $<0.001$ \\
\hline \multicolumn{4}{|l|}{ Family economics } \\
\hline Poor & 1 & (Ref.) & (Ref.) \\
\hline Good & 0.55 & $(0.35-0.84)$ & 0.007 \\
\hline \multicolumn{4}{|l|}{ Speaking about diabetes with friends } \\
\hline No & 1 & (Ref.) & (Ref.) \\
\hline Yes & 0.42 & $(0.27-0.66)$ & $<0.001$ \\
\hline Wish for more parental involvement & 1.56 & $(1.25-1.94)$ & $<0.001$ \\
\hline High blood glucose values to avoid hypos in different situations & 1.17 & $(1.09-1.26)$ & $<0.001$ \\
\hline
\end{tabular}

\section{To what extent is it important to talk to your doctor about...}

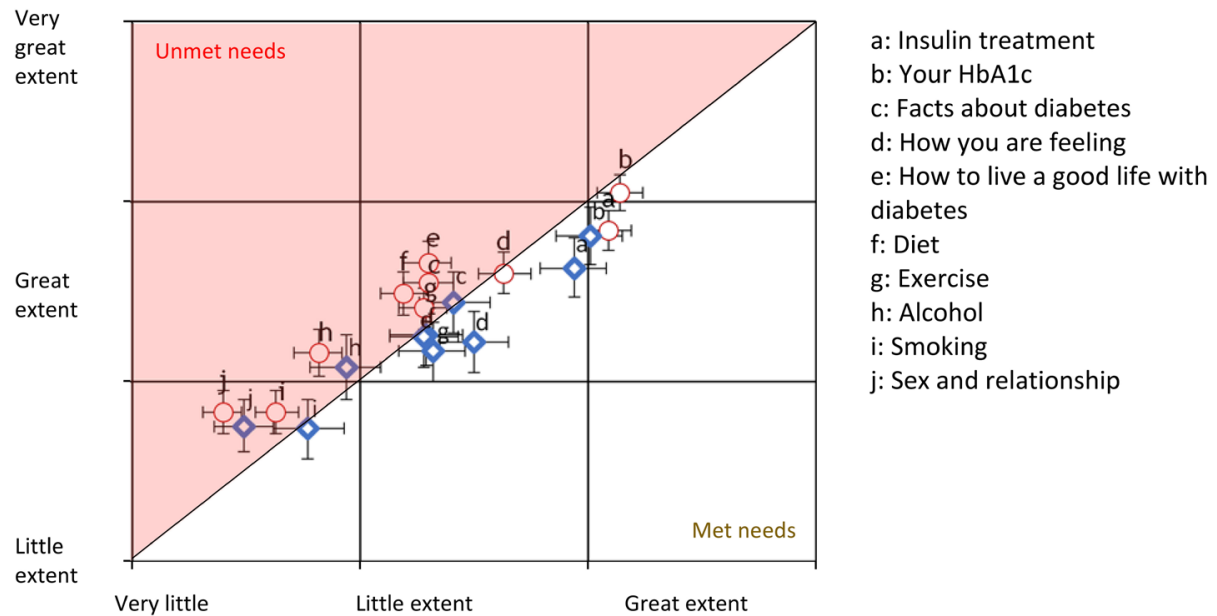

To what extent do you already talk to your doctor about...

Figure 2. Gender differences in self-assessed met and unmet needs when talking to with the pediatric diabetologist among 298 girl respondents and 155 boy respondents. Note: Red circles corresponds to girls. Blue circles correspond to boys. Error bars represent two-sided $95 \%$ confidence limits for the mean values. The figure is based on two questions. Question 1: "To what extent is it important for you to talk to your doctor about ..." with the following possible answer categories: 1 = "Very little extent"; 2 = "Little extent"; 3 = "Great extent"; $4=$ "Very great extent". Question 2: "To what extent do you already talk to your doctor about ..." with the following possible answer categories: 1 = "Very little extent"; 2 = "Little extent"; 3 = "Great extent"; 4 = "Very great extent". 


\subsection{Diabetes Distress and Expectations of the Outpatient Visit}

Among the girls with self-reported diabetes distress all discussion topics, except insulin treatment and $\mathrm{HbAlc}$, were reported as unmet (Figure 3) Girls with diabetes distress reported a significantly less interest in discussing insulin treatment, their HbAlc value, and diet in comparison to girls without diabetes distress $(\mathrm{p}<0.05)$. Girls with diabetes distress also reported that they talked significantly less about "how they were feeling" and "how to live a good life with diabetes" with their pediatric diabetologist than girls without diabetes distress.

Among boys with diabetes distress $(n=29)$ most discussion topic was met with the exception of some life style topics (Figure 4). No statistical differences were found between boys with and without diabetes distress regarding the deemed importance of various discussion themes and what they reported they talked about (data not shown).

\section{Discussion}

An adolescent outpatient visit can be challenging for both the patient and the health care provider since the adolescent is in a period of dramatic physical, cognitive, and emotional transformation which is going to influence their approach to the management of their diabetes. The success of the outpatient visit varies among people, culture, setting and situation [19] [20] [21].

To what extent is it important to talk to your doctor

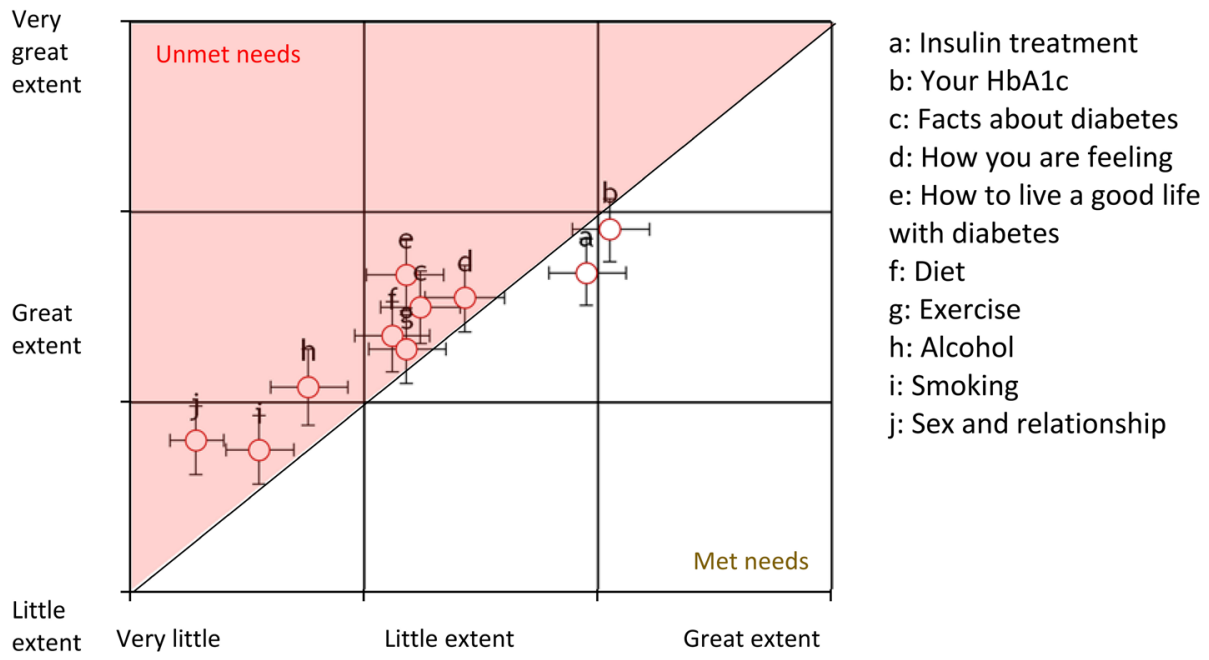

To what extent do you already talk to your doctor about...

Figure 3. Met and unmet needs when talking to the paediatric diabetologist among 130 girl respondents with diabetes distress (DDS-2 score $\geq 3$ ). Note: Error bars represent two-sided 95\% confidence limits for the mean values. The figure is based on two questions. Question 1: "To what extent is it important for you to talk to your doctor about ..." with the following possible answer categories: 1 = "Very little extent"; 2 = "Little extent"; 3 = "Great extent"; 4 = "Very great extent". Question 2: "To what extent do you already talk to your doctor about ..." with the following possible answer categories: 1 = "Very little extent"; 2 = "Little extent"; 3 = "Great extent"; 4 = "Very great extent". 
To what extent is it important to talk to your doctor

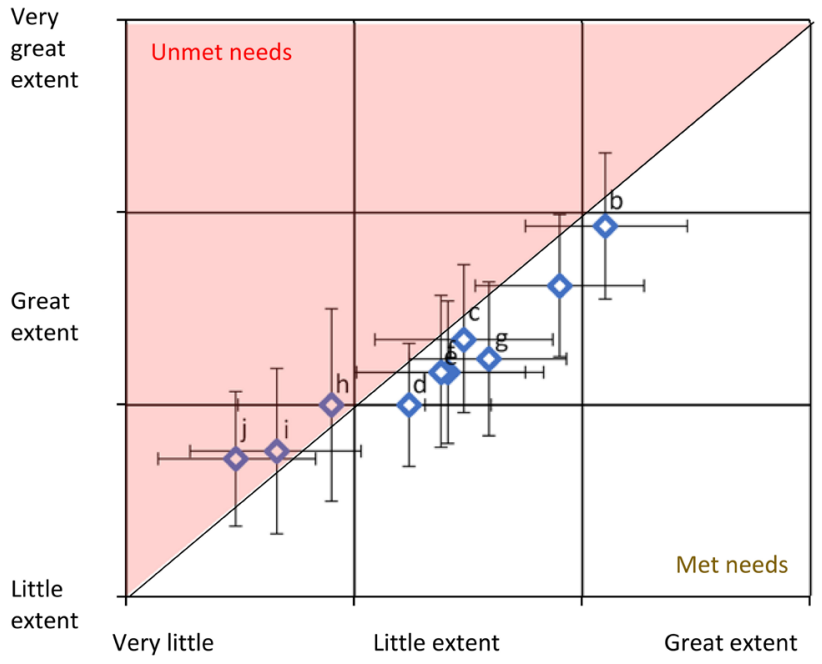

To what extent do you already talk to your doctor about...

Figure 4. Met and unmet needs when talking to the paediatric diabetologist 29 boy respondents with diabetes distress (DDS-2 score $\geq 3$ ). Note: Error bars represent two-sided 95\% confidence limits for the mean values. The figure is based on two questions. Question 1: "To what extent is it important for you to talk to your doctor about ..." with the following possible answer categories: 1 = "Very little extent"; 2 = "Little extent"; 3 = "Great extent"; $4=$ "Very great extent". Question 2: "To what extent do you already talk to your doctor about ..." with the following possible answer categories: 1 = "Very little extent"; 2 = "Little extent"; 3 = "Great extent"; 4 = "Very great extent".

One of the most important parts of the outpatient visit is to support the adolescents' ability and self-management diabetes to optimise insulin treatment and prevent future cardiovascular complications. Today, the aim of modern diabetes care besides promoting a high quality-of-life is to target an HbAlc as close to normal as possible without severe hypoglycaemia or a significant amount of nonsevere hypoglycaemia, or high glucose variability [22]. This study shows that the adolescents are aware of the importance of HbAlc targets and appropriate insulin treatment as these topics are the discussion topics with highest importance among both girls and boys (Figure 2).

Girls rated most topics as more important for discussion than boys and were more likely to feel that their expectations were unmet (Figure 3). Diabetes related topics might generally not be favourable topics to discuss among some adolescents (Figure 2). However, if these topics are discussed, participants in another study stated that it was the pediatric diabetologist who was the person they are most likely to discuss them with [20].

Our findings, however, show that girls with diabetes distress feel that their need for information and discussion on nearly all topics was unmet, even such topics that were considered less important, e.g. smoking and alcohol. Interestingly however, girls with less favourable metabolic control who also reported more diabetes distress (Table 3 ) wanted to discuss HbAlc and insulin treatment significantly less ( $p<0.05$ only among girls) (Figure 5). Possibly this is because 


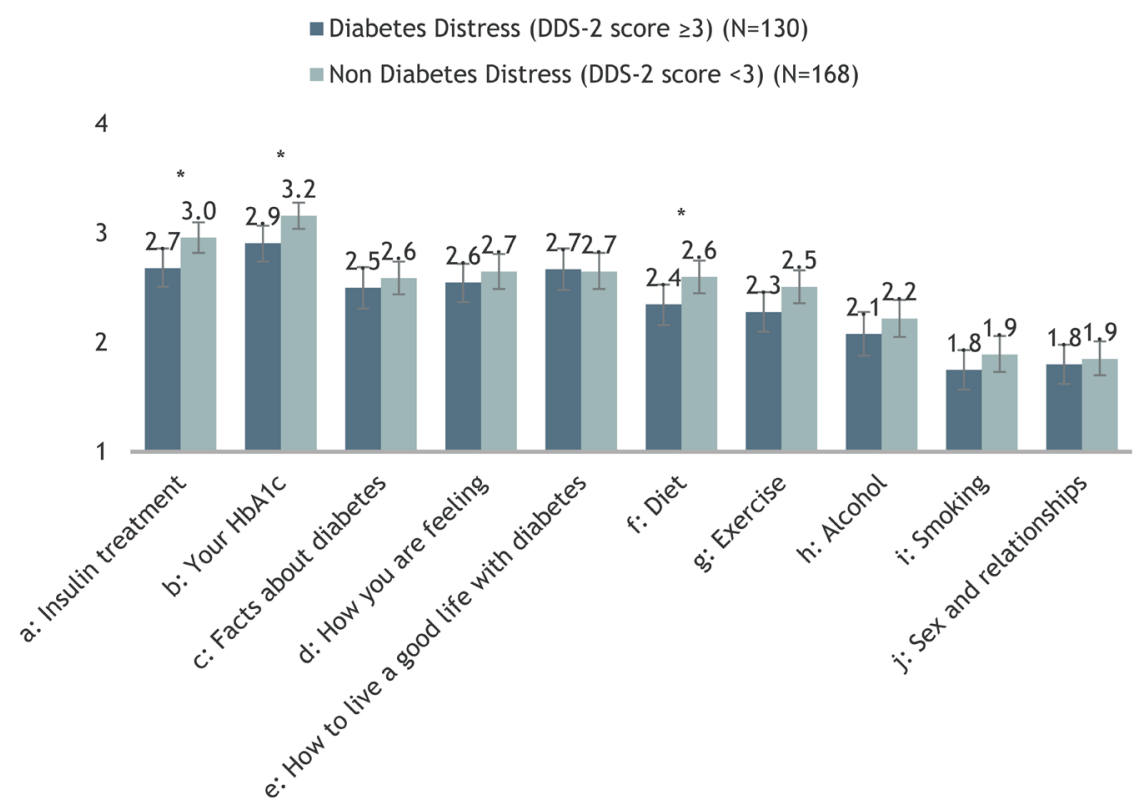

Figure 5. Differences in reporting the importance of various discussion themes with the physician among 298 girl respondents with and without diabetes distress. Note: ${ }^{\star}$ represent p-values $<0.05$ indicating significant differences in mean values between girls with and without diabetes distress. Error bars represent two-sided 95\% confidence limits for the mean values. The figure is based on the question: "To what extent is it important for you to talk to your doctor about ..." with the following possible answer categories: $1=$ "Very little extent"; 2 = "Little extent"; 3 = "Great extent"; 4 = "Very great extent".

such topics usually are a predominate part of the discussion in the consultations and some girls want more focus to be put on aspects of diabetes related quality of life.

Exercise has a protective psychological and cardiovascular impact on children with T1D [23], and it is essential that HCP regularly promote and discuss the importance of exercise. Older children and adolescents with T1D are generally less physically active than their non-T1D peers [23] [24]. This gender difference in exercise patterns may already be established before the age of seven, where girls with T1D exercise less than boys with T1D [3] [25]. In our study, although both girls and boys were interested in discussing exercise the girls with diabetes distress wishes were unmet by the consultation (Figures 2-4).

Smoking and alcohol were themes rated as less important by the adolescents to talk about and topics that were rarely discussed (Figure 2). This contrasts with the fact that among the respondents $14 \%$ of the boys and $18 \%$ of the girls self-reported smoking at least once during the previous week (Table 2). Nearly all adult smokers initiate their smoking behaviour before the age of 18 years [26] [27]. However, available data suggest that less than $50 \%$ of adolescents with T1D state that they do not remember ever being counselled by their HCP about smoking [27]. Even though the effect of smoking on the vascular system is usually not yet apparent among adolescents, it is still warranted to regularly discuss the risks of smoking and promote smoking cessation to prevent future cardio- 
vascular complications [28]. Smoking has also been shown to be significantly correlated to alcohol consumption [29]. Based on a large-scale assessment of the national diabetes registry in Germany and Austria, it was shown that $13 \%$ of adolescents aged 16 - 18 self-reported alcohol use during the previous year [29]. The rates of severe hypoglycaemia and DKA were significantly higher among alcohol users [29]. Even though the adolescents did not express a wish to speak about smoking and alcohol, both factors are associated with significant health risks. Thus, HCPs should regularly discuss both alcohol and smoking with adolescents.

Sex and relationships were also themes rated as less important by the adolescents to talk about and topics that were rarely discussed (Figure 2). A national survey of adults in France with childhood onset of T1D showed that both young men and women with T1D were less satisfied with their sex lives than the general population [30]. Moreover, a teenage pregnancy is always a high-risk pregnancy both socially and medically and having T1D will further increase this risk. In the outpatient visit, sex and relationships should therefore be discussed with a minimum requirement, to inform adolescents about e.g. relevant contraception. There is also the possibility to refer adolescents to a specialised Youth Health Centre.

This study shows that almost half of the girls and one-fifth of the boys ( $44 \%$ vs. 19\%) suffered from self-reported diabetes distress. Diabetes distress has often been related to a decline in self-management behaviours and suboptimal plasma glucose levels [13]. This study demonstrated the significance of six variables associated with an increased risk of suffering from diabetes distress: HbAlc value > $52 \mathrm{mmol} / \mathrm{mol}$ (6.9\%), being a girl, perceived poor family economy, not speaking about diabetes with friends, wishing for more parental involvement, and adapting a high blood glucose strategy to prevent hypoglycaemia (Table 3 ).

Girls with diabetes distress were significantly more reluctant to speak about insulin treatment, their HbAlc level and diet habits than girls without diabetes distress (Figure 5). These are all sensitive subjects that may trigger anxiety in an adolescent that already has unpleasant stress related to diabetes. Overall, adolescent girls with diabetes distress reported that most of their discussion needs were unmet. A pronounced individualized care includes a multi-professional team approach where a psychologist and a social worker should be available.

Since the need to discuss various topics at the outpatient clinic visit varies depending on gender and possible presence of diabetes distress, an agenda setting approach is recommended [31] [32]. Adolescents should be encouraged prior to the outpatient visit to think about the issues to discuss. The consultation should be planned with a shared agenda in mind. This could be done at home, or in the waiting area before the consultation, either on paper or using verbal memory cues on mobile platforms. This agenda setting approach highlights the adolescents' wishes. This individualized person centred approach would better meet the adolescents' discussion needs and support a shared decision making between the adolescent and the health care professional [19]. 


\subsection{Strengths and Weaknesses of the Study}

This survey was part of a national study where all adolescents aged 15 to $<18$ years in SWEDIABKIDS were invited to complete an online questionnaire. The SWEDIABKIDS registry includes data on almost all (approximately 99\%) children and adolescents with diabetes under the age of 18 years in Sweden. The questionnaire was developed in collaboration with pediatric diabetologists, survey experts and focus group adolescents. Through focus group interviews, it was confirmed that the questions included in the survey were important for adolescents.

As with many other questionnaire-based studies targeted at teenagers, there was a relatively low rate of participation and the fact that girls participated more often than boys did. To consider the gender difference in response rate we separated the analyses for girls and boys. With the help of the data from the national register (SWEDIABKIDS) we were able to perform an analysis of non-respondents. The average $\mathrm{HbAlc}$ was $60 \mathrm{mmol} / \mathrm{mol}$ (SD: 15) (7.7\%, SD: 3.5) in respondents and $66 \mathrm{mmol} / \mathrm{mol}$ (SD: 16) (8.2\%, SD: 3.6) in non-respondents. This discrepancy in $\mathrm{HbAlc}$ levels has to be viewed in the light of the current situation in Sweden where T1D patients aged $15-17.99$ years have an average $\mathrm{HbAlc}$ value of 57.6 $\mathrm{mmol} / \mathrm{mol}$ (7.4\%) (2020 SWEDIABKIDS) which is well below the level of the participants in the study. The HbAlc is a dynamic value which fortunately has an overall declining trend in Sweden. Generally, $\mathrm{HbAlc}$ increases during adolescence and our data reflects the age population well. Our research aims to identify which kind of support is preferred among adolescents with problems.

\subsection{Conclusion}

In summary, adolescents' expectations are in general met in this study but show a gender difference, both regarding the expected discussion topics and what was deemed to be discussed. Multiple aspects of living with diabetes are however perceived not to be sufficiently met among girls with diabetes distress. Boys' discussion topics were significantly more likely to be met. A multi-professional, individual person-centred care approach is needed at the diabetes outpatient clinic. A proposed shared agenda-setting process initiated by the adolescent prior to the outpatient clinic visit could facilitate individualized care and better meet the adolescents' needs in a shared decision-making process.

\section{Acknowledgements}

Many thanks to Mette Bøgelund, S.E. Stallknecht and Henrik Holm Jensen, Incentive, Denmark for valuable statistical support.

\section{Conflicts of Interest}

The authors declare no conflicts of interest regarding the publication of this paper. 


\section{References}

[1] Cho, Y.H., Craig, M.E. and Donaghue, K.C. (2014) Puberty as an Accelerator for Diabetes Complications. Pediatric Diabetes, 15, 18-26.

https://doi.org/10.1111/pedi.12112

[2] Schwab, K.O., Doerfer, J., Marg, W., Schober, E., Holl, R.W., Initiative, D.P.V.S., et al. (2010) Characterization of 33488 Children and Adolescents with Type 1 Diabetes Based on the Gender-Specific Increase of Cardiovascular Risk Factors. Pediatric Diabetes, 11, 357-363. https://doi.org/10.1111/j.1399-5448.2010.00665.x

[3] Åkesson, K., Eriksson, E., Fureman, A.L., Gudbjörnsdottir, S., Hanberger, L. and Pundziute-Lyckå, A. (2017) Swediabkids Annual Report 2017-The Swedish Childhood Diabetes Registry.

[4] Brown, T.L., Maahs, D.M., Bishop, F.K., Snell-Bergeon, J.K. and Wadwa, R.P. (2016) Influences of Gender on Cardiovascular Disease Risk Factors in Adolescents with and without Type 1 Diabetes. International Journal of Pediatric Endocrinology, 2016, Article No. 8. https://doi.org/10.1186/s13633-016-0026-6

[5] Anderzen, J., Samuelsson, U., Gudbjornsdottir, S., Hanberger, L. and Akesson, K. (2016) Teenagers with Poor Metabolic Control Already Have a Higher Risk of Microvascular Complications as Young Adults. Journal of Diabetes and its Complications, 30, 533-536. https://doi.org/10.1016/j.jdiacomp.2015.12.004

[6] Hanberger, L., Samuelsson, U., Lindblad, B. and Ludvigsson, J. (2008) A1C in Children and Adolescents with Diabetes in Relation to Certain Clinical Parameters: The Swedish Childhood Diabetes Registry SWEDIABKIDS. Diabetes Care, 31, 927-929. https://doi.org/10.2337/dc07-1863

[7] Holl, R.W., Swift, P.G., Mortensen, H.B., Lynggaard, H., Hougaard, P., Aanstoot, H.J., et al. (2003) Insulin Injection Regimens and Metabolic Control in an International survey of Adolescents with Type 1 Diabetes over 3 Years: Results from the Hvidore Study Group. European Journal of Pediatrics, 162, 22-29. https://doi.org/10.1007/s00431-002-1037-2

[8] Herzer, M. and Hood, K.K. (2010) Anxiety Symptoms in Adolescents with Type 1 Diabetes: Association with Blood Glucose Monitoring and Glycemic Control. Journal of Pediatric Psychology, 35, 415-425. https://doi.org/10.1093/jpepsy/jsp063

[9] Kovacs, M., Goldston, D., Obrosky, D.S. and Bonar, L.K. (1997) Psychiatric Disorders in Youths with IDDM: Rates and Risk Factors. Diabetes Care, 20, 36-44. https://doi.org/10.2337/diacare.20.1.36

[10] Rechenberg, K., Whittemore, R. and Grey, M. (2017) Anxiety in Youth with Type 1 Diabetes. Journal of Pediatric Nursing, 32, 64-71.

https://doi.org/10.1016/j.pedn.2016.08.007

[11] Chaplin, J.E., Hanas, R., Lind, A., Tollig, H., Wramner, N. and Lindblad, B. (2009) Assessment of Childhood Diabetes-Related Quality-of-Life in West Sweden. Acta Paediatricar, 98, 361-366. https://doi.org/10.1111/j.1651-2227.2008.01066.x

[12] Forsander, G., Bogelund, M., Haas, J. and Samuelsson, U. (2017) Adolescent Life with Diabetes-Gender Matters for Level of Distress. Experiences from the National TODS Study. Pediatric Diabetes, 18, 651-659. https://doi.org/10.1111/pedi.12478

[13] Delamater, A.M., de Wit, M., McDarby, V., Malik, J.A., Hilliard, M.E., Northam, E., et al. (2018) ISPAD Clinical Practice Consensus Guidelines 2018: Psychological Care of Children and Adolescents with Type 1 Diabetes. Pediatric Diabetes, 19, 237-249. https://doi.org/10.1111/pedi.12736

[14] Forsander, G., Stallknecht, S., Samuelsson, U., Marcus, C. and Bøgelund, M. (2018) 
Preferences for Treatment among Adolescents with Type 1 Diabetes: A National Study Using a Discrete Choice Experiment Model. Diabetic Medicine, 35, 621-629. https://doi.org/10.1111/dme.13592

[15] National Diabetes Registry (NDR)-SWEDIABKIDS. https://swediabkids.ndr.nu

[16] Joensen, L.E., Tapager, I. and Willaing, I. (2013) Diabetes Distress in Type 1 Diabetes-A New Measurement Fit for Purpose. Diabetic Medicine, 30, 1132-1139. https://doi.org/10.1111/dme.12241

[17] Polonsky, W.H., Fisher, L., Earles, J., Dudl, R.J., Lees, J., Mullan, J., et al. (2005) Assessing Psychosocial Distress in Diabetes: Development of the Diabetes Distress Scale. Diabetes Care, 28, 626-631. https://doi.org/10.2337/diacare.28.3.626

[18] Fisher, L., Glasgow, R.E., Mullan, J.T., Skaff, M.M. and Polonsky, W.H. (2008) Development of a Brief Diabetes Distress Screening Instrument. Annals of Family Medicine, 6, 246-252. https://doi.org/10.1370/afm.842

[19] Herlitz, A., Munthe, C., Torner, M. and Forsander, G. (2016) The Counseling, Self-Care, Adherence Approach to Person-Centered Care and Shared Decision Making: Moral Psychology, Executive Autonomy, and Ethics in Multi-Dimensional Care Decisions. Health Communication, 31, 964-973. https://doi.org/10.1080/10410236.2015.1025332

[20] Boman, A., Bohlin, M., Eklof, M., Forsander, G. and Torner, M. (2015) Conceptions of Diabetes and Diabetes Care in Young People with Minority Backgrounds. Qualitative Health Research, 25, 5-15. https://doi.org/10.1177/1049732314549358

[21] Hartvigsson, T., Forsander, G. and Munthe, C. (2018) Error Trawling and Fringe Decision Competence: Ethical Hazards in Monitoring and Addressing Patient Decision Capacity in Clinical Practice. Clinical Ethics, 13, 126-136. https://doi.org/10.1177/1477750917749955

[22] Fullerton, B., Jeitler, K., Seitz, M., Horvath, K., Berghold, A. and Siebenhofer, A. (2014) Intensive Glucose Control versus Conventional Glucose Control for Type 1 Diabetes Mellitus. Cochrane Database of Systematic Reviews, 2, Article ID: CD009122. https://doi.org/10.1002/14651858.CD009122.pub2

[23] Trigona, B., Aggoun, Y., Maggio, A., Martin, X.E., Marchand, L.M., Beghetti, M., et al. (2010) Preclinical Noninvasive Markers of Atherosclerosis in Children and Adolescents with Type 1 Diabetes Are Influenced by Physical Activity. The Journal of Pediatrics, 157, 533-539. https://doi.org/10.1016/j.jpeds.2010.04.023

[24] Sarnblad, S., Ekelund, U. and Aman, J. (2005) Physical Activity and Energy Intake in Adolescent Girls with Type 1 Diabetes. Diabetic Medicine, 22, 893-899. https://doi.org/10.1111/j.1464-5491.2005.01544.x

[25] Sundberg, F., Forsander, G., Fasth, A. and Ekelund, U. (2012) Children Younger than 7 Years with Type 1 Diabetes Are Less Physically Active than Healthy Controls. Acta Paediatrica, 101, 1164-1169. https://doi.org/10.1111/j.1651-2227.2012.02803.x

[26] Backinger, C.L., Fagan, P., Matthews, E. and Grana, R. (2003) Adolescent and Young Adult Tobacco Prevention and Cessation: Current Status and Future Directions. Tobacco Control, 12, IV46-IV53. https://doi.org/10.1136/tc.12.suppl_4.iv46

[27] Mays, D., Streisand, R., Walker, L.R., Prokhorov, A.V. and Tercyak, K.P. (2012) Cigarette Smoking among Adolescents with Type 1 Diabetes: Strategies for Behavioral Prevention and Intervention. Journal of Diabetes and its Complications, 26, 148-153. https://doi.org/10.1016/j.jdiacomp.2012.03.005

[28] Shah, A.S., Dabelea, D., Talton, J.W., Urbina, E.M., D.Agostino, R.B.J., Wadwa, R.P., et al. (2014) Smoking and Arterial Stiffness in Youth with Type 1 Diabetes: The 
SEARCH Cardiovascular Disease Study. The Journal of Pediatrics, 165, 110-116. https://doi.org/10.1016/j.jpeds.2014.02.024

[29] Hermann, J.M., Meusers, M., Bachran, R., Kuhnle-Krahl, U., Jorch, N., Hofer, S.E., et al. (2017) Self-Reported Regular Alcohol Consumption in Adolescents and Emerging Adults with Type 1 Diabetes: A Neglected Risk Factor for Diabetic Ketoacidosis? Multicenter Analysis of 29630 Patients from the DPV Registry. Pediatric Diabetes, 18, 817-823. https://doi.org/10.1111/pedi.12496

[30] Mellerio, H., Guilmin-Crepon, S., Jacquin, P., Labeguerie, M., Levy-Marchal, C. and Alberti, C. (2015) Long-Term Impact of Childhood-Onset Type 1 Diabetes on Social Life, Quality of Life and Sexuality. Diabetes \& Metabolism, 41, 489-497. https://doi.org/10.1016/j.diabet.2014.12.006

[31] Gobat, N., Kinnersley, P., Gregory, J.W., Pickles, T., Hood, K. and Robling, M. (2015) Measuring Clinical Skills in Agenda-Mapping (EAGL-I). Patient Education and Counseling, 98, 1214-1221. https://doi.org/10.1016/j.pec.2015.06.018

[32] Gobat, N., Kinnersley, P., Gregory, J.W. and Robling, M. (2015) What Is Agenda Setting in the Clinical Encounter? Consensus from Literature Review and Expert Consultation. Patient Education and Counseling, 98, 822-829.

https://doi.org/10.1016/j.pec.2015.03.024 